\title{
Physical Education Teacher's Job Satisfaction and Burnout Levels in Relation to School's Sport Facilities
}

\section{Ilias Kroupis}

School of Physical Education \& Sport Sciences, Democritus University of Thrace, Greece, ikroupis@phyed.duth.gr

\section{Olga Kouli}

School of Physical Education \& Sport Sciences, Democritus University of Thrace, Greece, okouli@phyed.duth.gr

\section{Thomas Kourtessis}

School of Physical Education \& Sport Sciences, Democritus University of Thrace, Greece,tkourtes@phyed.duth.gr

The purpose of this study was a) to assess job satisfaction and burnout among Greek Physical Education (PE) teachers and b) investigate how school sport facilities affect their job satisfaction and burnout levels. Two hundred and eightytwo Greek PE teachers, aged from 24 to 65 years old, participated in the study. Their working experience ranged from one to 37 years. The Employee Satisfaction Inventory (Koustelios \& Bagiatis, 1997) was employed to assess job satisfaction and the Maslach Burnout Inventory (Maslach \& Jackson, 1986) for the measurement of burnout. The results revealed that Greek PE teachers seem to be more satisfied by work itself and supervision and dissatisfied by promotion and even more by pay while experiencing medium to low burnout. Furthermore, Greek PE teachers who work in schools with very satisfactory sport facilities seem to be more satisfied in comparison to Greek PE teachers who work in poor sport facilities. Finally, Greek PE teachers who work in schools with very satisfactory sport facilities seem to experience lower burnout levels. It is thus recommended that schools should have the best sport equipment possible, for more satisfied, less burned-out PE teachers.

Keywords: physical education, sport facilities, job satisfaction, burnout, school

\section{INTRODUCTION}

Despite the plethora of studies on both job satisfaction and burnout at school working environments, the impact of the existing sport facilities on PE teachers' satisfaction and

Citation: Kroupis, I., Kouli, O., \& Kourtessis, T. (2019). Physical Education Teacher's Job Satisfaction and Burnout Levels in Relation to School's Sport Facilities. International Journal of Instruction, 12(4), 579-592. https://doi.org/10.29333/iji.2019.12437a 
burnout levels remains unexplored. The present study aimed at addressing this matter by exploring the job satisfaction and burnout levels of Greek PE teachers and investigating how these levels are affected by the existence of school's sport facilities.

According to Chelladurai (1999), satisfaction at work in the management and industrial psychology field, is perhaps the most frequently studied topic. Many researchers have attempted to define and describe the concept of job satisfaction. Job satisfaction is stated as a multidimensional concept in all definitions (Rice, McFarlin \& Bennett, 1989).

Job satisfaction affects positively and significantly teacher's performance at schools, meaning that the higher teacher job satisfaction, the higher teacher performance (Arifin, 2015). It is of great importance to examine teachers' job satisfaction within the school environment, since it affects their performance, which in turn may affect students' performance as well (Davis \& Wilson, 2000; Shann, 1998). Studies conducted in Greece (Kouli et al., 2015; Koustelios, 2001;) revealed that educators from both primary and secondary education in Greece, showed high levels of satisfaction in relation to their work and supervisors and low levels of satisfaction in relation to their payment and opportunities for promotion. Secondary PE teachers in particular, seemed to be satisfied by job itself and less satisfied by supervisor and working conditions. On the contrary, they were dissatisfied by pay and organization as a whole (Koustelios \& Tsigilis, 2005). Statistically significant differences were found between PE teachers and other teachers, who teach different subjects in Greece (Antoniou, Kourtessis, Koustelios, \& Papaioannou, 2007). More specifically, except for the pay factor where all educators showed relatively low levels of satisfaction, PE teachers seemed to be more satisfied in relation to primary and secondary teachers of all subjects.

Another issue worth investigating is the dependence of PE teachers on sport facilities and equipment, plus the fact that they have to teach under different weather conditions away from the shelter of the classroom (Koustelios \& Tsigilis, 2005) and the effect it may cause to the job satisfaction levels. According to Aldridge and Fraser (2016), resource adequacy influenced job satisfaction directly and positively. The term resource adequacy was referring to the extent to which facilities, finance, equipment and resources were suitable and adequate to support personnel. Teachers from Chicago and Washington D.C. rated the working conditions in their schools (degree of overcrowding, availability and adequacy of specialized facilities, psychological factors) and how they perceived these conditions affected their job performance and teaching effectiveness (Schneider, 2003). Specifically, while physical education and recreational facilities were considered essential to student well-being and achievement, were nevertheless rated not very or not at all adequate by almost 30 percent of Chicago teachers and 40 percent of Washington teachers. Among unsatisfied teachers who graded their facilities with low grades, more than 40 percent said that poor conditions had led them to consider changing schools and 30 percent were thinking about leaving teaching (Schneider, 2003).

For the last three decades the concept of burnout has been widely reported in the fields of psychology and sociology. It has been acknowledged that burnout can have side 
effects on a person's job or family life (Hellesøy, Grønhaug, \& Kvitastein, 2000). This has led to a large, multileveled and constantly enriched research attempt. The question of definition was one of the first controversies among the scholars. However, an underlying consensus of three core dimensions of the burnout syndrome existed, which led to the development of the multidimensional theory of burnout (Maslach, 1982). The most widely used definition of burnout, which comes from Maslach and Jackson (1986, p.1) depicts these three dimensions: "Burnout is a syndrome of emotional exhaustion, depersonalization and reduced personal accomplishment that can occur among individuals who do 'people work' of some kind."

The importance of burnout, both for the individual and the workplace, lies in its relations to some significant outcomes. Job burnout seems to significantly predict reduced job satisfaction and increased turnover intention, while reduced job satisfaction also seem to significantly predict increased turnover intention (Lu \& Gursoy, 2016). A negative relationship between job satisfaction and burnout has also been addressed (Kroupis et al., 2017). In relation to health outcomes, the most common assumption is that burnout causes mental dysfunction, such as anxiety, depression, low self-esteem etc. (Maslach, Schaufeli, \& Leiter, 2001). Teacher's burnout is one of the most serious problems found in schools (van Horn, Schaufeli, Greenglass, \& Burke, 1997). Teacher's job performance is negatively affected by burnout and hence, the reduced teaching quality may have an effect on student's academic performance (Blandford, 2000) or/and the general educational system in general (Hughes, 2001).

Research concerning the relationship between PE teachers and burnout is also limited. In Israel, PE teachers had demonstrated lower levels of burnout in comparison to teachers who work inside the class (Fejgin, Ephraty, \& Ben-Sira, 1995). Greek PE teachers reported relatively low levels of emotional exhaustion and depersonalization (Koustelios, 2003), in comparison to the levels presented by Maslach and Jackson (1986). Koustelios and Tsigilis (2005), also report low levels of burnout for Greek secondary PE teachers. One cause for the low levels of burnout for the Greek PE teachers could be the declined tendency in demands and expectations for the particular subject, from both the parents-students group and the PE teachers group as well (Koustelios \& Tsigilis, 2005). Moreover, the subject's heavy dependency on the availability of school's sport facilities and equipment, leads the PE teachers, in case of lacking this equipment, to improvise. This improvising may lead to a sense of increased autonomy, which in turn may contribute to the interpretation of the low burnout levels found for the Greek PE teachers (Koustelios \& Tsigilis, 2005). It is indeed that Pines (1993) reports that autonomy is negatively correlated with burnout. On the other hand, though Maslach and Schaufeli (1993) report that a common conclusion from a number of studies is that poor working conditions lead to burnout. According to this admission, the lack of sport facilities and equipment in schools could be addressed as a 'poor working condition', thus PE teachers who experience this condition should exhibit higher levels of burnout. What's more, low student motivation seems to be more strongly associated with the teachers' depersonalization, job satisfaction, and motivation to leave the teaching profession (Skaalvik \& Skaalvik, 2017). According to this admission, the lack of sport facilities and equipment in schools could lead to low student 
motivation, thus more burned-out, less satisfied PE teachers. In other findings (Wang, Hall, \& Rahimi, 2015) teachers who seem to strongly believe in their ability to engage their students in learning and classroom activities, not only reported higher job satisfaction and lower burnout levels, but also reported less frequent illness symptoms. Especially in physical education classes, sport facilities and equipment play an important role in engaging the students the learning process and sport activities. Qualitative data analyses indicated that. According to Richards, Hemphill, \& Templin, (2018), low-burnout teachers perceived their teaching environments as supportive, whereas their high-burnout colleagues felt as if their workplaces were constraining. One could assume that a school with a good level of sport facilities and equipment, would reflect a supportive workplace for PE teachers. It is obvious that no such singledimensional explanations exist in the case of PE teachers' burnout in relation to the school sport facilities and equipment and that further investigation is needed.

The Job Demands-Resources model could be used as a base for correlating school sport facilities with burnout. The main idea lies on the assumption that whereas every occupation may have its own specific risk factors associated with job stress, these factors can be classified in two general categories: a) job demands and b) job resources (Bakker, Demerouti, De Boer, \& Schaufeli, 2003). Examples of job demands are a high work pressure, an unfavorable physical environment and emotionally demanding interactions with clients (in our case the students). Job demands can be turned into job stressors when meeting those demands requires high effort and is therefore associated with high costs that elicit negative responses like sleeping problems, depression, anxiety or burnout (Doi, 2005; Schaufeli \& Bakker, 2004). Job resources on the other hand refer to those physical, psychological, social or organizational aspects of the job that are either/or a) functional in achieving work goals, b) reduce job demands and the associated physiological and psychological costs and c) stimulate personal growth, learning and development (Baker \& Demerouti, 2007). Furthermore, job resources have shown a significant negative relation to teacher well-being indicator: burnout (BermejoToro, Prieto-Ursúa, \& Hernández, 2016). Based on the above statements, it may be assumed that the lack of school sport facilities could characterize an unfavorable physical environment, thus raising job demands, thus raising burnout. On the contrary, very satisfactory school sport facilities represent those job resources that, according to the above statements, could contribute in constraining burnout.

According to the above, it seems that there is a deficiency in literature concerning PE teachers' job satisfaction and burnout levels in relation to the school sport facilities. So, the purpose of this study was: a) to assess job satisfaction and burnout among Greek PE teachers and compare with previous studies and b) investigate how school sport facilities effect Greek PE teachers' job satisfaction and burnout levels. 


\section{METHOD}

\section{Participants}

Two hundred and eighty-two Greek physical education (PE) teachers from primary and secondary public and private schools participated in the study. One hundred and thirtyseven were male $(48.6 \%)$ and one hundred and forty-five female $(51.4 \%)$. Their mean age was $43.6(\mathrm{SD}=5.45$, range 24-65) and their mean working experience was 14.5 ( $\mathrm{SD}=7.23$, range 1-37). The sample came from Athens, due to the large number of private schools included, in order to obtain a sufficient number of physical education teachers who work in schools with very good sport facilities.

\section{Instruments}

The Employee Satisfaction Inventory (ESI, Koustelios \& Bagiatis, 1997) was used to assess PE teacher's job satisfaction. ESI consists of 24 items, which measures six aspects of a job: the work itself (four items, e.g., my job is boring), pay (four items, e.g., paid less than I deserve), promotion (three items e.g., my perspective for promotiondevelopment is very limited), supervision (four items, e.g., my supervisor is rude), working conditions (five items, e.g., dangerous for my health) and organization as a whole (four items, e.g., the best school/institution I've ever worked). The internal consistencies (Cronbach's alpha) for each aspect were: for work itself (.77), for pay (.79), for promotion (.62), for supervision (.82), for working conditions (.80) and for organization as a whole (.76). Responses were given to a 5-point scale ranging from strongly agree (5) to strongly disagree (1). The reason why ESI was preferred as a measuring instrument, was because it has been developed and validated in the Greek cultural context. Its good psychometric properties have been supported in several studies (Koustelios, 2001; Koustelios \& Bagiatis, 1997; Koustelios \& Tsigilis, 2005).

The educator's version of the Maslach Burnout Inventory (MBI-ES) (Maslach \& Jackson, 1986) was used to measure job burnout. This instrument has been modified and validated for the Greek population by Kantas and Vassilaki (1997), and Kokkinos, (2006). The inventory consists of twenty two items which measure the three dimensions of burnout: emotional exhaustion (nine items, e.g., at the end of the school day I feel exhausted), depersonalization (five items, e.g., I feel disappointed by my job) and personal accomplishment (eight items, e.g., I've achieved many worthy things in my job). For emotional exhaustion and depersonalization, higher scores represent higher levels of burnout, whereas for personal accomplishment, lower scores represent higher levels of burnout. The internal consistencies (Cronbach's alpha) for each aspect were: for emotional exhaustion (.81), for depersonalization (.60) and for personal accomplishment (.86). Responses were provided to a 7-point Likert scale ranging from never (0) to every day (6).

In order to place school sport facilities into various levels, a questionnaire was used, where PE teachers wrote down just the number, not the condition of their schools' sport facilities. Due to a high degree of subjectivity of what consists a "good" or "bad" sport facility and after conducting a small pilot study on the matter, all schools were placed on 
three levels, based on the number of their sport facilities: a) poor, b) satisfactory, c) very satisfactory. As poor were characterized schools, which had up to 1 outdoor football field $(5 \times 5)$, or handball field, or volleyball field, or basketball field, or indoor gymnasium, or outdoor track and field, with/without a multiple usage room. Satisfactory were characterized those schools which had 2 outdoor fields of football, handball, volleyball, basketball, track and field, indoor gymnasium (or any combination), with/without a multiple usage room. Very satisfactory were characterized those schools which had more than 3 fields, with/without a multiple usage room. On the same questionnaire PE teachers were filling data like gender, years of experience, level of education and school type (private, public).

\section{Procedure}

The ESI, MBI and sport facilities questionnaires were administered to physical education teachers. Questionnaires were completed during PE consultants' gatherings and on school premises. Participation was voluntary. It was made clear to the participants that their responses would be held in strict confidence and will be used for academic purposes only.

\section{Data analysis}

One independent variable was used in the present study: school sport facilities (poor/satisfactory/very satisfactory). Nine dependent factors were used: six from the ESI (the work itself, pay, promotion, supervision, working conditions, organization as a whole) and three from the MBI questionnaire (emotional exhaustion, depersonalization, personal accomplishment). Cronbach's alpha was used to assess subscales internal consistency. MANOVAs were used to investigate possible differences between the subscales of the independent variable. SPSS 18 was used for computing all the above calculations. Significance level was set to .05 .

\section{FINDINGS}

In Table 1 the descriptive statistics and the Cronbach's alpha rates are presented. ESI subscale scores range from 1 (totally disagree) to 5 (totally agree) and they represent the mean score of the corresponding items. BMI subscale scores range from 0 (never) to 6 (every day). MBI subscale scores are the sum of the corresponding items. The higher the values on experienced emotional exhaustion, the higher the degree of burnout. 
Table1

Descriptive Statistics and Cronbach's Alpha of the ESI and MBI Subscales

\begin{tabular}{lllllll}
\hline & $\mathrm{N}$ & Min & Max & Mean & \multicolumn{2}{l}{ Std. Deviation Cronbach a } \\
\hline working conditions & 258 & 1.40 & 5 & 3.86 & 0.79 & 0.76 \\
pay & 262 & 1 & 5 & 2.25 & 1.12 & 0.84 \\
promotion & 260 & 1 & 5 & 2.46 & 0.95 & 0.73 \\
work itself & 269 & 2.25 & 5 & 4.28 & 0.57 & 0.70 \\
supervision & 269 & 1.25 & 5 & 4.06 & 0.72 & 0.85 \\
Organization as a whole & 264 & 1.25 & 5 & 3.41 & 0.85 & 0.76 \\
emotional exhaustion & 234 & 0 & 48 & 19.82 & 9.94 & 0.82 \\
personal accomplishment & 234 & 14 & 48 & 40.91 & 5.9 & 0.76 \\
depersonalization & 257 & 0 & 17 & 3.04 & 3.67 & 0.59 \\
\hline
\end{tabular}

Differences due to school sport facilities

In Table 2 the means of the ESI subscales for the school sport facilities are presented.

Table 2

Means of the ESI Subscales for School Sport Facilities

\begin{tabular}{llll}
\hline Job satisfaction factors & School sport facilities & mean & Std. Deviation \\
\hline \multirow{3}{*}{ working conditions } & poor & $3.37 \dagger$ & .69 \\
& satisfactory & $3.58^{*}$ & .66 \\
& very satisfactory & $4.15^{* \dagger}$ & .76 \\
pay & poor & $1.95^{*}$ & .94 \\
& satisfactory & $1.51^{*}$ & .76 \\
promotion & very satisfactory & $2.71^{*}$ & 1.14 \\
& poor & $1.93 \dagger$ & .73 \\
\multirow{3}{*}{ work itself } & satisfactory & $2.11^{*}$ & .68 \\
& very satisfactory & $2.84^{* \dagger}$ & .94 \\
\multirow{3}{*}{ supervision } & poor & 4.18 & .63 \\
& satisfactory & 4.16 & .62 \\
& very satisfactory & 4.34 & .51 \\
organization as a whole & poor & 3.97 & .67 \\
& satisfactory & 4.10 & .70 \\
& very satisfactory & 4.10 & .75 \\
& poor & $3.20 \dagger$ & .75 \\
& satisfactory & $3.17 *$ & .78 \\
& very satisfactory & $3.53 * \dagger$ & .87 \\
\hline
\end{tabular}

Note: $*, \dagger=$ statistically different

A multivariate analysis of variance (MANOVA) was used to examine the possible differences of the school sport facilities in relation to the depended variables: working conditions, pay, promotion, work itself, supervision and organization as a whole. The overall analysis was significant, $F(12,424)=8.244, \mathrm{p}<.001$. In the separate one-way analysis of variance (ANOVA's) that followed, statistically significant differences were found for working conditions $F(2,219)=24.785$, p<.001, pay $F(2,219)=26.069$, $\mathrm{p}<.001$, promotion $F(2,219)=25.890, \mathrm{p}<.001$ and organization as a whole $F(2,219)=$ $4.772, \mathrm{p}<.001$. For the independent variables of work itself and supervision, no 
statistically significant differences were found. For tracing the statistically significant differences, the multiple comparison LSD test was applied.

In Table 3 the means of the MBI subscales for the school sport facilities are presented.

Table 3

Means of the MBI Subscales for School Sport Facilities

\begin{tabular}{llll}
\hline Burnout factors & school & Mean & Std. Deviation \\
\hline Emotional exhaustion & poor & $22.20^{*}$ & 9.81 \\
& satisfactory & 20.20 & 9.60 \\
& very satisfactory & $18.15^{*}$ & 10.17 \\
Personal & poor & 42.44 & 4.13 \\
accomplishment & satisfactory & 40.22 & 6.91 \\
& very satisfactory & 40.84 & 5.82 \\
depersonalization & poor & 3.28 & 3.29 \\
& satisfactory & 2.03 & 2.59 \\
& very satisfactory & 2.77 & 3.88 \\
\hline
\end{tabular}

Note: $*$ statistically different

A multivariate analysis of variance (MANOVA) was used to examine the possible differences of the school sport facilities in relation to the depended variables: emotional exhaustion, personal accomplishment and depersonalization. The overall analysis was significant, $F(6,386)=3.108, \mathrm{p}<.01$. In the separate analysis of variance (ANOVA's) that followed, statistically significant differences were only found for emotional exhaustion $F(2,197)=3.058, \mathrm{p}<.05$. For tracing the statistically significant differences, the multiple comparison LSD test was applied and results revealed statistically significant differences between poor and very satisfactory school sport facilities.

\section{DISCUSSION}

The purpose of this study was: a) to assess job satisfaction and burnout among Greek PE teachers and compare with previous studies and $b$ ) investigate how school sport facilities effect Greek PE teachers' job satisfaction and burnout levels. Similar studies revealed that Greek educators are more satisfied from their job, while their burnout levels are low compared to educators from other countries (Kantas \& Vassilaki, 1997; Koustelios \& Tsigilis, 2005).

In relation to the mean job satisfaction subscales scores, it seems that PE teachers are more satisfied by work itself and supervision, followed by working conditions and organization as a whole. Greek PE teachers are dissatisfied by promotion and even more by pay. As for the mean burnout scores and according to the norms of Maslach, Jackson and Leiter (1996), PE teachers in Greece seem to experience medium levels of emotional exhaustion, and low levels of depersonalization and personal accomplishment. In other words, they experience medium to low burnout. However, these findings, should be compared with extreme caution to Maslach's norms, since according to Schaufeli and Dierendock (1995), such comparisons should be made with great reservation. They claim that the differences found in the levels of the burnout subscales could be due to the sociocultural differences existing in each country. As seen 
by the study, Greek PE teachers should perhaps have more chances for promotion and better wages. Given the current socioeconomic situation though, the latter seems a utopia. As for promotion opportunities, these should be given not only counting years of duty, but also from other occasions like personal educational development, success in domestic school sport games, innovative teaching methods etc.

Despite the medium levels of burnout that Greek PE teachers experience, it should be noted that tracing previous scores in Greek PE teachers' emotional exhaustion, the range was around fifteen (Koustelios, 2003; Koustelios \& Tsigilis, 2005; Tsigilis et al., 2011). In the present study though, the score of the emotional exhaustion raised to almost twenty. Since the emotional exhaustion dimension of burnout is considered to be the main and most autonomous element of burnout (Maslach et al., 1996; Rohland et al., 2004), it could be assumed that Greek PE teachers have a tendency to a gradual experience of burnout levels. Causes for such tendency are not easy to be identified. Perhaps a feeling of a lack of real backup on behalf of the state/supervisor, the sudden changes in the working conditions such as school merging, abolition of school subject specialties or the emergence of an uncertain environment in general, in relation to the rapid negative socioeconomic changes, may have led to higher burnout.

In relation to the school sport facilities and job satisfaction levels, statistically significant differences were found for working conditions, pay, promotion and organization as a whole. That is, PE teachers working in schools with very satisfactory sport facilities were more satisfied than PE teachers who worked in schools with poor sport facilities, in relation to the subscales mentioned above. The specific outcomes may perhaps justify teachers' intention to change schools or abandon teaching, due to low job satisfaction levels as a result of poor school facility conditions (Aldridge \& Fraser, 2016; Shneider, 2003). It could be perhaps understandable when a PE teacher works in a school where the only 'sport' facility the school has is a small concrete front yard, (a situation that can be found in urban schools of Athens-Greece for example), that her satisfaction levels compared to another colleague who works in a more 'suitable' sport environment, could be lower. The PE teacher who works in poor sport facility conditions, has to work harder in order to figure out activities that can be done in such poor conditions. The PE teacher also has to figure out a variety of activities that will contribute to decrease possible boredom signs on behalf of the students, since the lack of any sport facilities leave students with fewer choices. In fact, it could be said that poor school sport facility situations depict a misery situation, where this can have an impact on job satisfaction levels.

As for school sport facilities and burnout, differences were only mentioned for emotional exhaustion, where PE teachers working in schools with poor sport facilities, scored higher scores than their colleagues who worked in schools with very satisfactory ones. The specific dimension though is considered to be the most important one, being the main and more autonomous element of burnout (Maslach et al., 1996; Rohland et al., 2004). Koustelios and Tsigilis (2005) point out that the medium burnout levels of the Greek PE teachers could be contributed to the following thoughts; PE classes are heavily depended on the availability of facilities and equipment. When such facilities do 
not exist, the PE teacher has to improvise, something which might lead to a sense of increased autonomy, thus less burnout. By the findings of the current study though, it seems that the poorest the sport facilities, the biggest the burnout levels among PE teachers. In Maslach and Schaufeli's (1993) study the conclusion that poor working conditions lead to burnout is mentioned. If thus, the lack of school sport facilities is considered to be a poor working condition, Maslach and Schaufeli's statement seems to be confirmed.

Trying to expound the findings of the current study in relation to burnout, the Job Demands-Resources model could be of help. According to the model (Bakker, et al., 2003), every occupation may have its own specific risk factors associated with job stress. These factors can be classified in two general categories, job demands and job resources. Examples of job demands are a high work pressure, an unfavourable physical environment and emotionally demanding interactions with clients (in our case students) (Baker \& Demerouti, 2007). Although job demands are not necessarily negative, they may turn into job stressors, such as depression, anxiety or burnout (Schaufeli \& Baker, 2004). On the other hand, job resources refer to those physical, psychological, social or organizational aspects of the job that are functional in achieving work goals, either/or reduce job demands (Baker \& Demerouti, 2007). It has been also proposed that job resources may isolate the impact of job demands on job strain, including burnout (Bakker, et al., 2003), meaning that job resources are negatively related to burnout (Bermejo-Toro et al., 2016). Based on the above statements, it could be supported that the lack of school sport facilities defines an unfavourable working environment, raising the job demands level, hence raising burnout level. On the contrary, very satisfactory school sport facilities constitute the job resources that according to the above, contribute to the restriction of burnout, something which also came out of the current study's findings.

Some limitations of the present study should be kept in mind when interpreting the results. Firstly, it should be noted that since the sample was consisted of PE teachers only, generalizing the findings to other teachers should be avoided. Secondly, the questionnaires were handed out during PE teachers' meetings with PE school consultants. Thus, it may be that some of them did not pay the proper attention when filling the questionnaires and just wanted to get through with it. Another limitation of the current study could be the degree of subjectivity of what consists of a "poor" or "satisfactory" school sport facility. The main idea was to measure the number of sport facilities, not their condition. Again, the number of a "poor" school sport facility for example, could be a subject for an argument.

\section{CONCLUSION}

Greek PE teachers seem to be more satisfied by work itself and supervision, followed by working conditions and organization as a whole. Greek PE teachers are dissatisfied by promotion and even more by pay. As for the mean burnout scores and according to the norms of Maslach et al. (1996), PE teachers in Greece seem to experience medium levels of emotional exhaustion, and low levels of depersonalization and personal accomplishment. In other words, they experience medium to low burnout. Nevertheless, 
the levels of emotional exhaustion found to be higher in relation to previous studies, revealing an increasing tendency. School sport facilities seem to influence the job satisfaction and burnout levels in a way that PE teachers working in schools with poor sport facilities, are less satisfied and more burned out that their colleagues who work in schools with better sport facilities.

Future studies could investigate the school sport equipment threshold, where the PE teacher is satisfied enough, less burned out, in order to implement the physical education lesson. Future studies could try to investigate further the conversation of the "good" or "poor" school sport facility. In addition, future studies could also try to include the sport equipment(s) that is/are necessary for a physical education lesson and how that, might affect PE teachers' job satisfaction and burnout levels.

\section{REFERENCES}

Aldridge, J. M., \& Fraser, B. J. (2016). Teachers' views of school climate and its relationship with teacher self-efficacy and job satisfaction. Lea. Env. R., 19(2), 291-307.

Antoniou, C., Kourtessis, T., Koustelios, A., \& Papaioannou, A. (2007). Comparing physical educators' job satisfaction levels with other subject educators. Sport \& Society, 45, 76-82.

Arifin, H. M. (2015). The influence of competence, motivation, and organizational culture to high school teacher job satisfaction and performance. Int. Ed. Stu, 8(1), 38-45.

Bakker, A. B., \& Demerouti, E. (2007). The job demands-resources model: State of the art. Journal of Managerial Psychology, 22(3), 309-328.

Bakker, A. B., Demerouti, E., de Boer, E., \& Schaufeli, W. B. (2003). Job demands and job resources as predictors of absence duration and frequency. Journal of Vocational Behavior, 62(2), 341-356.

Bakker, A. B., Demerouti, E., Taris, T. W., Schaufeli, W. B., \& Schreurs, P. J. G. (2003). A multigroup analysis of the job demands-resources model in four home care organizations. Int. J. of Stress Manag., 10(1), 16-38. doi:10.1037/1072-5245.10.1.16.

Bermejo-Toro, L., Prieto-Ursúa, M., \& Hernández, V. (2016). Towards a model of teacher well-being: Personal and job resources involved in teacher burnout and engagement. Educational Psychology, 36(3), 481-501.

Blandford, S. (2000). Managing professional development in schools. London: Routledge Falmer.

Chelladurai, P. (1999). Human resource management in sport and recreation. Champaign: Human Kinetics Publishers.

Davis, J., \& Wilson, S. M. (2000). Principals' efforts to empower teachers: Effects on teacher motivation and job satisfaction and stress. The Clearing House, 73(6), 349-353. 
Doi, Y. (2005). An epidemiologic review on occupational sleep research among Japanese workers. Industrial Health, 43(1), 3-10.

Fejgin, N., Ephraty, N., \& Ben-Sira, D. (1995). Work environment and burnout of physical education teachers. Journal of Teaching in Physical Education, 15(1), 64-78.

Hellesøy, O., Grønhaug, K., \& Kvitastein, O. (2000). Burnout: Conceptual issues and empirical findings from a new research setting. Scandi. J. of Manage., 16(3), 233-247.

Hughes, R. E. (2001). Deciding to leave but staying: Teacher burnout, precursors and turnover. International Journal of Human Resource Management, 12(2), 288-298.

Kantas, A., \& Vassilaki, E. (1997). Burnout in Greek teachers: Main findings and validity of the Maslach burnout inventory. Work \& Stress, 11(1), 94-100.

Kokkinos, C. M. (2006). Factor structure and psychometric properties of the Maslach Burnout Inventory educators survey among elementary and secondary school teachers in Cyprus. Stress and Health, 22(1), 25-33.

Kouli, O., Kourtessis, T., Tzetzis, G., Karkaletsi, F., Skordilis, E., \& Bonti, E. (2015). Job satisfaction and burnout of Greek secondary special education teachers. Journal of Physical Activity Nutrition and Rehabilitation, 1. PANR e-ISSN: 2421-7824

Koustelios, A. (2001). Personal characteristics and job satisfaction of Greek teachers. International Journal of Educational Management, 15(7), 354-358.

Koustelios, A. (2003). Burnout among physical education teachers in Greece. International Journal of Physical Education, 40(1), 32-38.

Koustelios, A., \& Tsigilis, N. (2005). The relationship between burnout and job satisfaction among physical education teachers: A multivariate approach. European Physical Education Review, 11(2), 189-203.

Koustelios, A. D., \& Bagiatis, K. (1997). The employee satisfaction inventory (ESI): Development of a scale to measure satisfaction of Greek employees. Educational and Psychological Measurement, 57(3), 469-476.

Kroupis, I., Kourtessis, T., Kouli, O., Tzetzis, G., Derri, V., \& Mavrommatis, G. (2017). Job satisfaction and burnout among Greek PE teachers. A comparison of educational sectors, level and gender. Cultura_Ciencia_Deporte, 12(34), 5-14.

Lu, A. C. C., \& Gursoy, D. (2016). Impact of job burnout on satisfaction and turnover intention: do generational differences matter? J. of Hosp. \& Tours. Res., 40(2), 210-235.

Maslach, C. (1982). Burnout: The cost of caring. Englewood Clifs, NJ: Prentice-Hall.

Maslach, C., \& Jackson, S. E. (1986). Maslach burnout inventory manual. Palo Alto, CA: Consulting Psychologists Press. 
Maslach, C., Jackson, S. E., \& Leiter, M. P. (1996). Maslach burnout inventory manual. Palo Alto, C.A.: Consulting Psychologists Press.

Maslach, C., \& Schaufeli, W. B. (1993). Historical and conceptual development of burnout. In W. Schaufeli, C. Maslach, \& T. Marek (Eds.), Professional burnout: Recent developments in theory and research (pp. 1-18). Washington, D.C.: Taylor \& Francis.

Maslach, C., Schaufeli, W. B., \& Leiter, M. P. (2001). Job burnout. Annual Review of Psychology, 52(1), 397-422.

Pines, M. A. (1993). Burnout: An existential perspective. In W. Schaufeli, C. Maslach, \& T. Marek (Eds.), Professional burnout: Recent developments in theory and research (pp. 33-51). Washington, D.C.: Taylor \& Francis.

Rice, R. W., McFarlin, D. B., \& Bennett, D. E. (1989). Standards of comparison and job satisfaction. Journal of Applied Psychology, 74(4), 591.

R. Richards, K. A., Hemphill, M. A., \& Templin, T. J. (2018). Personal and contextual factors related to teachers' experience with stress and burnout. Teachers and Teaching, 24(7), 768-787

Rohland, B. M., Kruse, G. R., \& Rohrer, J. E. (2004). Validation of a single-item measure of burnout against the Maslach burnout inventory among physicians. Stress and Health, 20(2), 75-79.

Schaufeli, W. B., \& Bakker, A. B. (2004), Job demands, job resources, and their relationship with burnout and engagement: a multi-sample study. Journal of Organizational Behavior, 25(3), 293-315.

Schaufeli, W., \& van Dierendonck, D. (1995). A cautionary note about the crossnational and clinical validity of the cut-off points for the Maslach Burnout Inventory. Psychological Report, 76, 1083-1090.

Schneider, M. (2003). Linking school facility conditions to teacher satisfaction and success. Washington, DC: National Clearinghouse for Educational Facilities.

Shann, M. H., (1998). Professional commitment and satisfaction among teachers in urban middle schools. The Journal of Educational Research, 92(2), 67-73.

Skaalvik, E. M., \& Skaalvik, S. (2017). Still motivated to teach? A study of school context variables, stress and job satisfaction among teachers in senior high school. Social Psychology of Education, 20(1), 15-37.

Tsigilis, N., Zournatzi, E., \& Koustelios, A. (2011). Burnout among physical education teachers in primary and secondary schools. Int. J. of Human. and Soc. Sci., 7(1), 53-58.

van Horn, J.E., Schaufeli, W.B., Greenglass, E.R., \& Burke, R.J. (1997). A CanadianDutch comparison of teacher's burnout. Psychological Reports, 81(2), 371-382. 
Wang, H., Hall, N. C., \& Rahimi, S. (2015). Self-efficacy and causal attributions in teachers: Effects on burnout, job satisfaction, illness, and quitting intentions. Teaching and Teacher Education, 47, 120-130. 